\title{
Correction to: Early Complications After Percutaneous Closure of Atrial Septal Defect in Infants with Procedural Weight Less than $15 \mathrm{~kg}$
}

\author{
Gustaf Tanghöj $^{1,2} \cdot$ Michal Odermarsky $^{3,4} \cdot$ Estelle Naumburg $^{1,2} \cdot$ Petru Liuba $^{3}$
}

Published online: 11 February 2021

๑) Springer Science+Business Media, LLC, part of Springer Nature 2021

\section{Correction to: Pediatric Cardiology (2017) 38:255-263 https://doi.org/10.1007/s00246-016-1507-3}

The Original version of the article has contained error in method part, page 256 it written:

The largest diameter of the ASD was measured from transesophageal echocardiography (TEE) images, being expressed in millimeter.

We used transesophageal echos as well as transthoracic echos.

The revise text is following:

The largest diameter of the ASD was measured from transesophageal echocardiography (TEE) or transthorasic echocardiography (TTE) images, being expressed in millimeter.

As well as both entities has been used in the article.

1. The ASD diameter/weight ratio was calculated using the largest measured ASD diameter (from TEE or TTE) divided by the child's weight at the procedure. The children were thereafter categorized in two groups using a cutoff ratio of 1.2. This value was earlier shown to be a risk factor for post-procedural complications.

The original article can be found online at https://doi.org/10.1007/ s00246-016-1507-3.

Gustaf Tanghöj

gustaf.tanghoj@regionjh.se

1 Department of Clinical Science Paediatrics, Umeå University, Umeå, Sweden

2 Unit of Research Education and Development, Östersund Hospital, Östersund, Sweden

3 Department of Cardiology, Pediatric Heart Center, Skåne University Hospital Lund, Lund University, Lund, Sweden

4 Department of Paediatrics, Blekinge Hospital, Karlskrona, Sweden
2. The ASD diameter/BSA ratio was calculated using the largest measured ASD diameter (from TEE of TTE) divided by the child's BSA at the procedure. The body surface area (BSA) was calculated using Haycock geometrical formula.

Publisher's Note Springer Nature remains neutral with regard to jurisdictional claims in published maps and institutional affiliations. 